

\section{EN EL CONTEXTO ACTUAL}

EN ESTE NÚMERO 6 de LA TADEO DEARTE un nuevo grupo de investigadores sigue preguntándose por el concepto, la materialización y la producción, y por los distintos valores socio-culturales y políticos de la imagen.

En el contexto de una pandemia global, con experiencias físicas y emocionales de incertidumbre generalizada y colectiva sin precedentes, que produce conexiones hasta ahora inimaginables y que no encuentra antecedentes similares desde la pandemia de gripe de 1918, la cuarentena permitió u obligó a cierta introspección en solitario que produjo no pocos desarrollos en distintos niveles.

Queremos agradecer a los autores que trabajaron con nosotros y respondieron a nuestras demandas editoriales aportando su punto de vista particular sobre el inmenso tema de la imagen. 


\section{SOBRE EL CONCEPTO DE IMAGEN}

COMO PUEDe Verse en los diferentes diccionarios de distintos idiomas, las definiciones de imagen hacen un recorrido conceptual que da a la palabra múltiples acepciones y que además, y por lo general, se superponen semánticamente: «figura, representación, semejanza y apariencia de algo»; "forma con la cual una cosa se le aparece al que la mira; forma de una cosa real recreada en el proceso artístico o reproducida con medios técnicos»; «recreación de la realidad a través de elementos imaginarios fundados en una intuición o visión del artista que debe ser descifrada; representación mental producida por la imaginación o recordada por la memoria»; «representación simbólica de un concepto abstracto; estatua, efigie o pintura de una divinidad o de un personaje sagrado»; «reproducción de la figura de un objeto por la combinación de los rayos de luz que proceden de él»; «formas que después de haber contemplado un objeto con mucha intensidad, persiste en el ojo, aunque con colores cambiados»; «la forma de presentarse, de ofrecerse a los demás»; "conjunto de rasgos que caracterizan ante la sociedad a una persona o a una entidad y así continúa».

Con este relevamiento -aunque parcial-, parecería práctico y válido epistemológicamente sostener que las tradicionales definiciones de cualquier concepto, siguen siendo solo un intento positivista para cerrar un tema desde el acotado «criterio de autoridad» en la «fijación de una creencia» (Peirce 2012: I, 172.188), creando una falsa seguridad e impidiendo un proceso más fructífero de investigación.

Este resultado nos permite afirmar que evidentemente hay una capacidad diferencial entre el lenguaje verbal y las imágenes respecto de la producción de significación. Cualquier tratado de retórica muestra que mediante el lenguaje verbal pueden construirse más de un centenar de figuras retóricas. ¿Sería posible ejemplificar una cantidad semejante de figuras retóricas mediante imágenes?' ${ }^{1}$ Dado que no se trata de una competencia deportiva sino de una fundamental herramienta de comunicación humana, resultaría de práctica utilidad, tratar de destacar la especificidad y la complementariedad de los lenguajes verbales y visuales.
Ferdinand de Saussure (1916 [1983], 139-142) sostenía ya hace más de 100 años que la relación entre el significado y el significante lingüístico era arbitraria e inmotivada, y que el signo lingüístico -ya sea acústico o visual-se desarrolla como una línea en el tiempo. Por el contrario, reconocía que el signo visual puede "ofrecer complicaciones simultáneas en varias dimensiones» (Saussure 1916 [1983], 141) o «coexistir en el espacio sin confundirse» (Saussure 1916 [1983], 176).

Durante el inicio de la incipiente discusión sobre el iconismo, Hugo Volli $(1972,19)$ decía -todavía bajo la influencia de la semiología saussuriana- que el «Iconismo implica la presencia de motivaciones formales en las relaciones no arbitrarias entre el signo y el objeto». Así es cómo los tres sistemas de representación visual conocidos -la Perspectiva, el Sistema Monge y el Lenguaje Gráfico TDE-, tienen tres intenciones ideológicas claramente diferenciales. ${ }^{2}$ Sin embargo, la palabra motivación es ambigua, ya que, si consideramos los distintos idiomas existentes, cada uno tuvo motivaciones diferentes para construir la misma realidad como un objeto diferente. De la misma manera, que los tres lenguajes gráficos [Fig. 1, 2 y 3] también construyen -cada uno- un aspecto diferente del mismo objeto: la Villa Rotonda de Palladio.

A pesar de lo dicho, vale la pena hacer notar cierta ambigüedad descriptiva de los lenguajes gráficos. Si comparamos la Casa Curutchet de Le Corbusier (1948) (deArte 4 2018, 11-12) con la Villa Rotonda de Palladio (1566), podríamos constatar que tanto la Perspectiva como la planta en Sistema Monge nos presentan dos objetos claramente distintos. Sin embargo, analizando los trazados y la configuración compleja representada mediante el Lenguaje Gráfico TDE (Guerri 2012), podemos verificar que la estructura morfosintáctica de diseño es muy semejante: la diferencia es quizás solo $15^{\circ}$ en el giro entre un cuadrado y otro. Coherencia en la simetría de rotación 8 en Palladio [Fig. 4] (deArte 42018 , 12) y obligada negación de la simetría en Le Corbusier [Fig. 3]. En definitiva, si cada lengua construye mundos diferentes, también la imagen muestra y significa solo aquello que el sistema de representación utilizado le permite. 


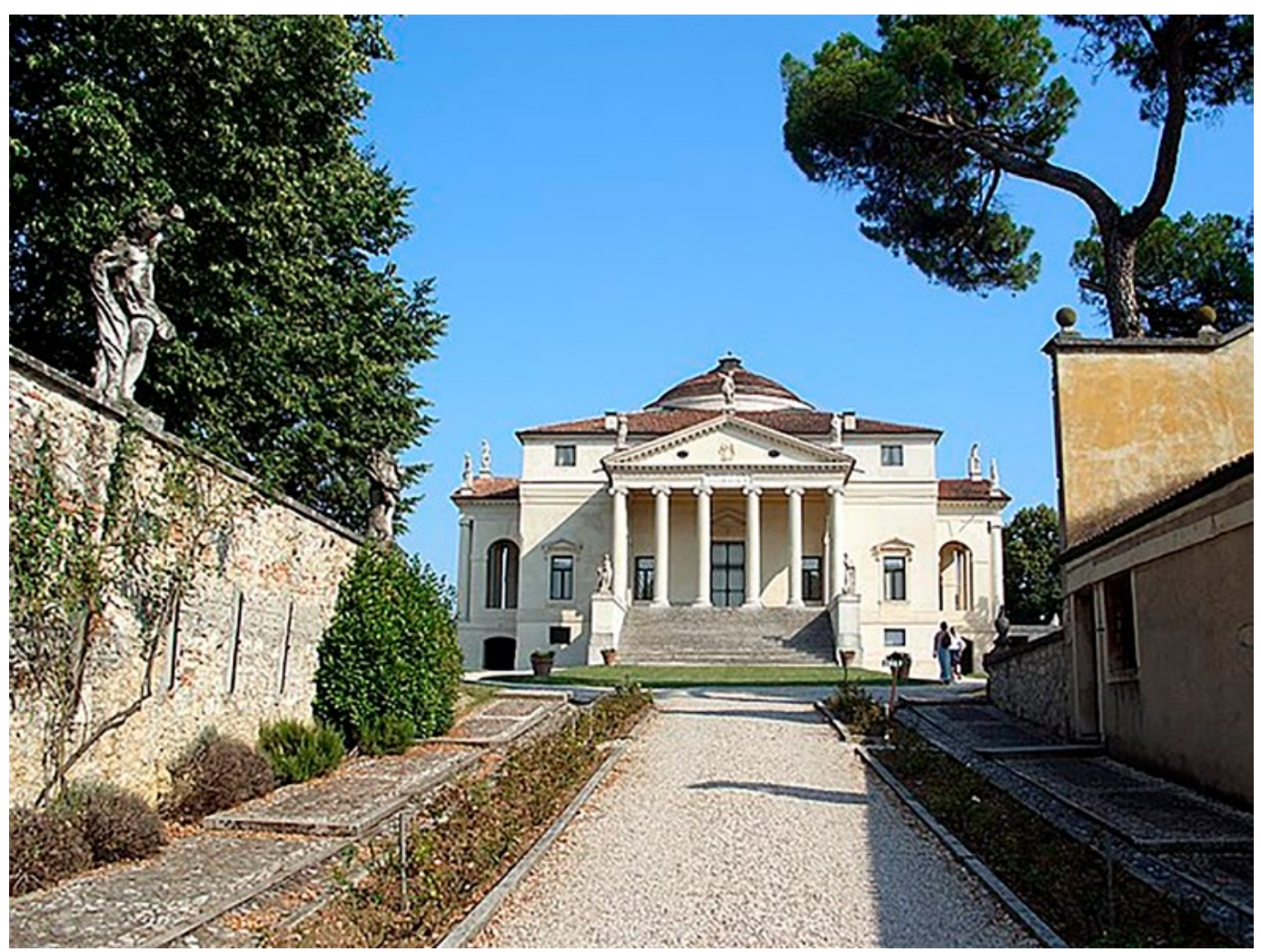

[ Figura 1. Vista mediante proyecciones cónicas fotográficas de la entrada a la Villa Capra -o Rotonda- en Vicenza, Italia. Nótese cómo Palladio, en 1566, diseña la entrada a la villa de tal manera que obliga a una visión en perspectiva de un punto de fuga central. La Perspectiva construye la cualidad del espacio habitable. ] Fuente: Wikipedia.

[ Figura 2. Planta y Corte vertical de la Villa Rotonda de Palladio. Representación realizada mediante proyecciones geométricas ortogonales o Sistema Monge por Sir Banister Fletcher (1896, 661), cuando una recopilación de obras de arquitectura mediante este sistema gráfico era aún una gran novedad. El Sistema Monge muestra la cantidad de materia que ocupa el espacio, nótese el detalle de las medidas dibujadas por el autor dando cuenta del valor mensurable del espacio arquitectónico al ser descrito y documentado para el constructor con este sistema. ] Fuente: Sir Banister Fletcher $(1896,661)$

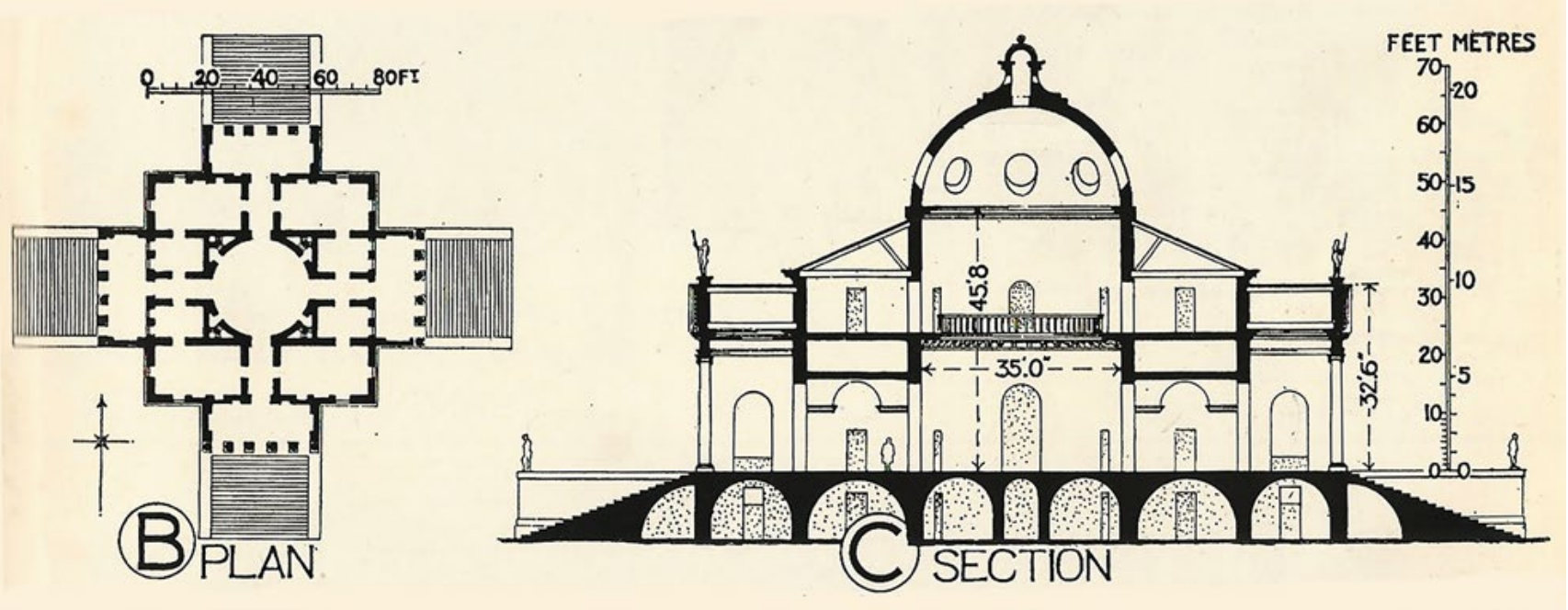




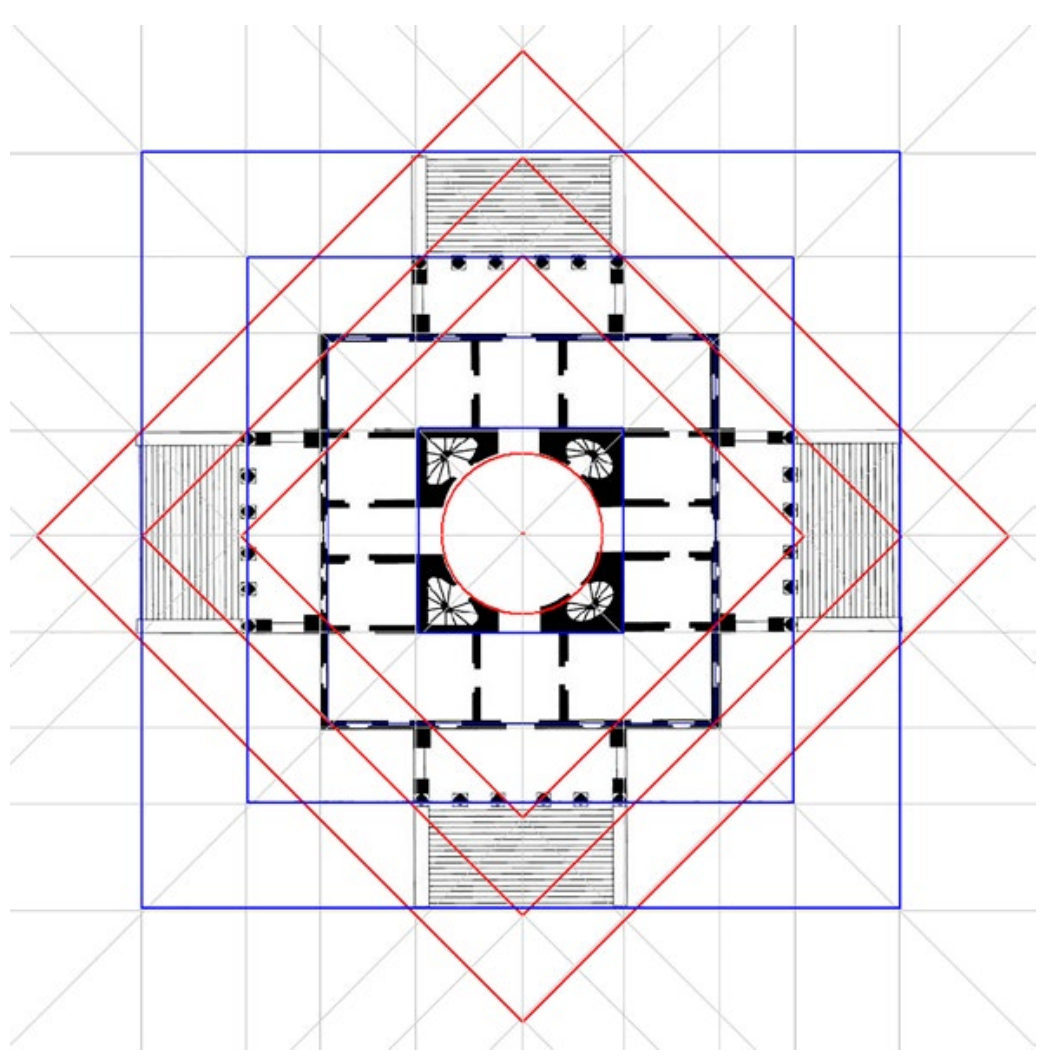

[ Figura 3. Trazados y configuración compleja mediante Proyecciones Relacionales - Lenguaje Gráfico TDE (Guerri 2012, 186), de la planta de la Villa Rotonda de Palladio. Esta imagen responde a una promesa de explicación conceptual morfosintáctica de la operación de diseño puro (Jannello 1980). ] Fuente: Elaboración propia.

\section{EL VALOR DE LA LUZ EN LA IMAGEN}

UN ANÁLISIS LÓGICO-SEMIÓTICO sobre los cinco sentidos podría aportar nueva luz sobre el rol de la imagen en el contexto de la producción de algún tipo de significación. Así, la pregnancia, potencia y eficacia de las imágenes puede ser atribuida -por lo menos parcialmente-, al rol que ocupa la visión en relación con los otros sentidos. Para cumplir con este objetivo, debemos reorganizar primeramente la lista -sin principio ni fin-, de los cinco o más sentidos que nos presenta la tradición. Con este objeto, la semiótica de base lógica, peircean ${ }^{a, 3}$ permite un reordenamiento interesante de esta concepción sociocultural a partir de considerar que todo signo puede ser analizado en sus tres aspectos: icónicos, indiciales y simbólicos. ${ }^{4}$ Desde esta lógica, los cinco sentidos serían sólo tre ${ }^{\mathrm{s}: 5}$

1. Visión que, a partir de la existencia de la luz, permite reconocer la diferencia de aspectos icónicos como el color, la textura visual y la forma;
2. Contacto -en tanto olfato, tacto y gusto-, que en relación con alguna materia habilitan sensaciones que permiten reconocer lo diferente, lo indicial, en los olores, en las texturas táctiles y en los sabores concretos; y

3. Audición, que relacionada con el sonido, obliga a una diferenciación simbólica para reconocerle al sonido valores de música, ruido o palabra.

A partir de este planteo lógico también podríamos inferir -dada la inevitabilidad de la invasión lumínica como sensación primera y primordial- la razón histórica por la cual la imagen fue siempre adorada o prohibida, amada o desconfiada, vista o negada. Actualmente, con las facilidades de la difusión de la impresión analógica y digital podemos aceptar ese lugar común de que vivimos en una «sociedad de la imagen», y también el conocido adagio de que «una imagen vale más que mil palabras». 


\section{ACERCA DEL \\ PODER PERFORMÁTICO DE LAS IMÁGENES}

EN 2013 LA revista italiana de semiótica Lexia invitó a escribir sobre Hacer cosas con imágenes, replicando el conocido título de las conferencias de 1955 de John Austin sobre Hacer cosas con palabras, temática que en el contexto de la teoría de los actos de habla consideraba la agentividad altamente convencionalizada del efecto simbólico de ciertos actos verbales. Aunque la mayoría de los artículos no se atuvieron estrictamente a la propuesta del llamado, el tema imagen dio origen a un voluminoso número más de 700 páginas en cuatro idiomas. Nuestro artículo La manumisión de las imágenes (Acebal et al. 2014, 71-90) -utilizando la metáfora de la liberación de esclavos en la antigua Roma- propuso una revisión y una expansión del concepto de performatividad desde una perspectiva peirceana. Escrito en colaboración con otros tres colegas, buscamos demostrar cómo el origen lingüístico del concepto de performatividad se limitaba solo a la naturaleza simbólica para esa noción del proceso semiótico como el habitual «Yo te bautizo...». Nuestro desafío consistió en que, gracias a la herramienta semiótica de base lógico peirceana, podíamos demostrar que además del nivel simbólico, debían tomarse en consideración también los niveles indiciales e icónicos. ${ }^{6}$

Pudimos sostener esta idea a partir de un evento concreto, la conmemoración de 2011 en recuerdo a los 10 años de la represión del 19 y 20 de diciembre de 2001. Esos dos días de manifestaciones fueron un enfrentamiento a la declaración de estado de sitio y, finalmente, produjeron la caída del gobierno argentino. En esta ocasión, los fotógrafos de la Asociación de Reporteros Gráficos de la República Argentina -ARGRA-, emplazaron -con el patrocinio de la Presidencia de la Nación-, en los mismos lugares de los acontecimientos del año 2001 y en los $2 \mathrm{~km}$ que separan la Plaza del Congreso de la Plaza de Mayo, una serie de gigantografías que documentaban los sucesos de 2001 a escala 1:1 [Fig. 4, 5, 6 y 7]. Así, el largo recorrido entre las dos plazas cubierto con estas gigantografías, hizo que el árbol de Navidad -que el gobierno de la ciudad emplazaba todos los años en la Plaza de Mayo- se vea como una afrenta y fuera incendiado [Fig. 8 y 9].

[ Figura 4. Fotografía del cartel emplazado sobre las rejas del Palacio del Congreso con los nombres y las edades de los caídos durante los dos días de diciembre 2001. La estrategia cromática -en tanto valores icónicos de la imagen-que construye significado en la lona, destaca desde el fondo negro color asociado al luto - no tanto los nombres de los muertos en rojo, cuanto las edades en blanco. ] Fuente: Cristina Voto.

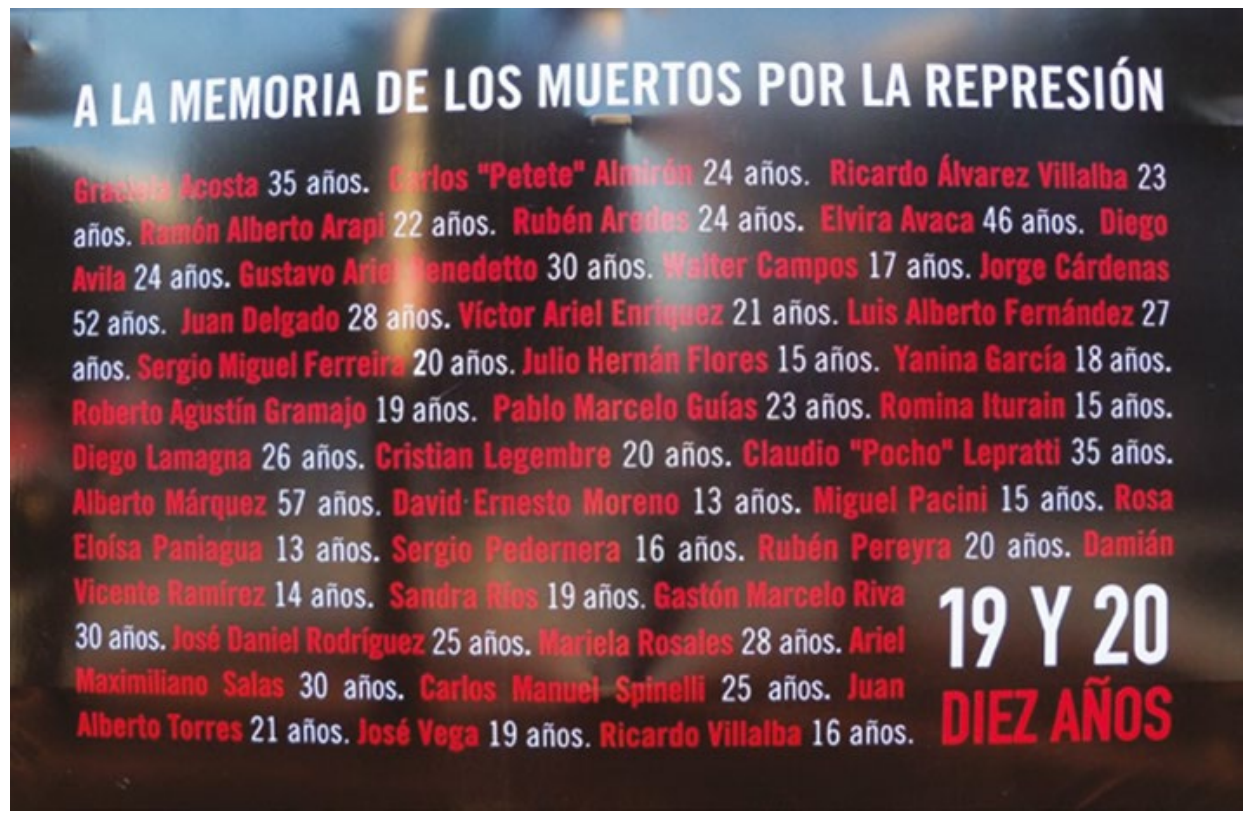




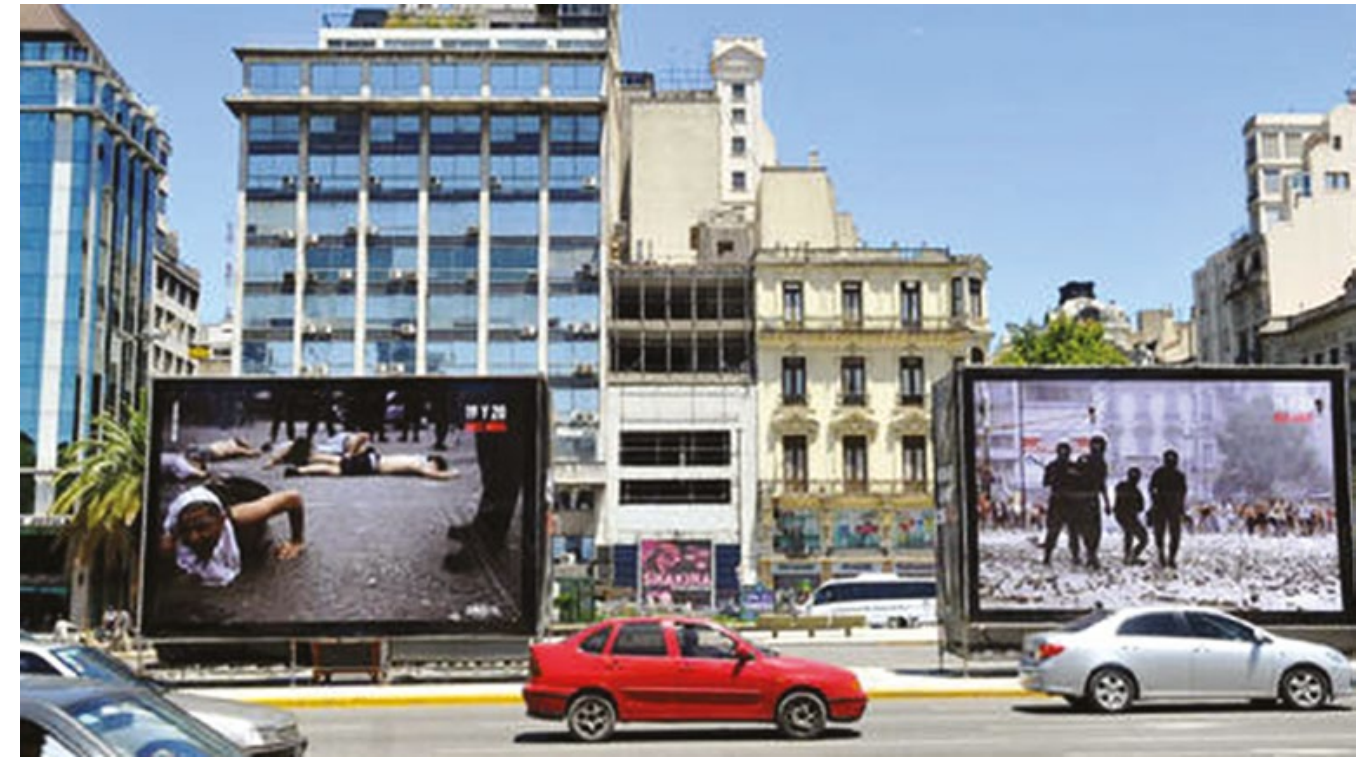

[ Figura 5. En esta fotografía puede reconocerse el tamaño que tuvieron las estructuras y las imágenes emplazadas en las avenidas. A diferencia de las imágenes emplazadas en el sitio mismo de la toma fotográfica original, éstas tienen un borde negro para separarlas del fondo. ] Fuente: ARGRA

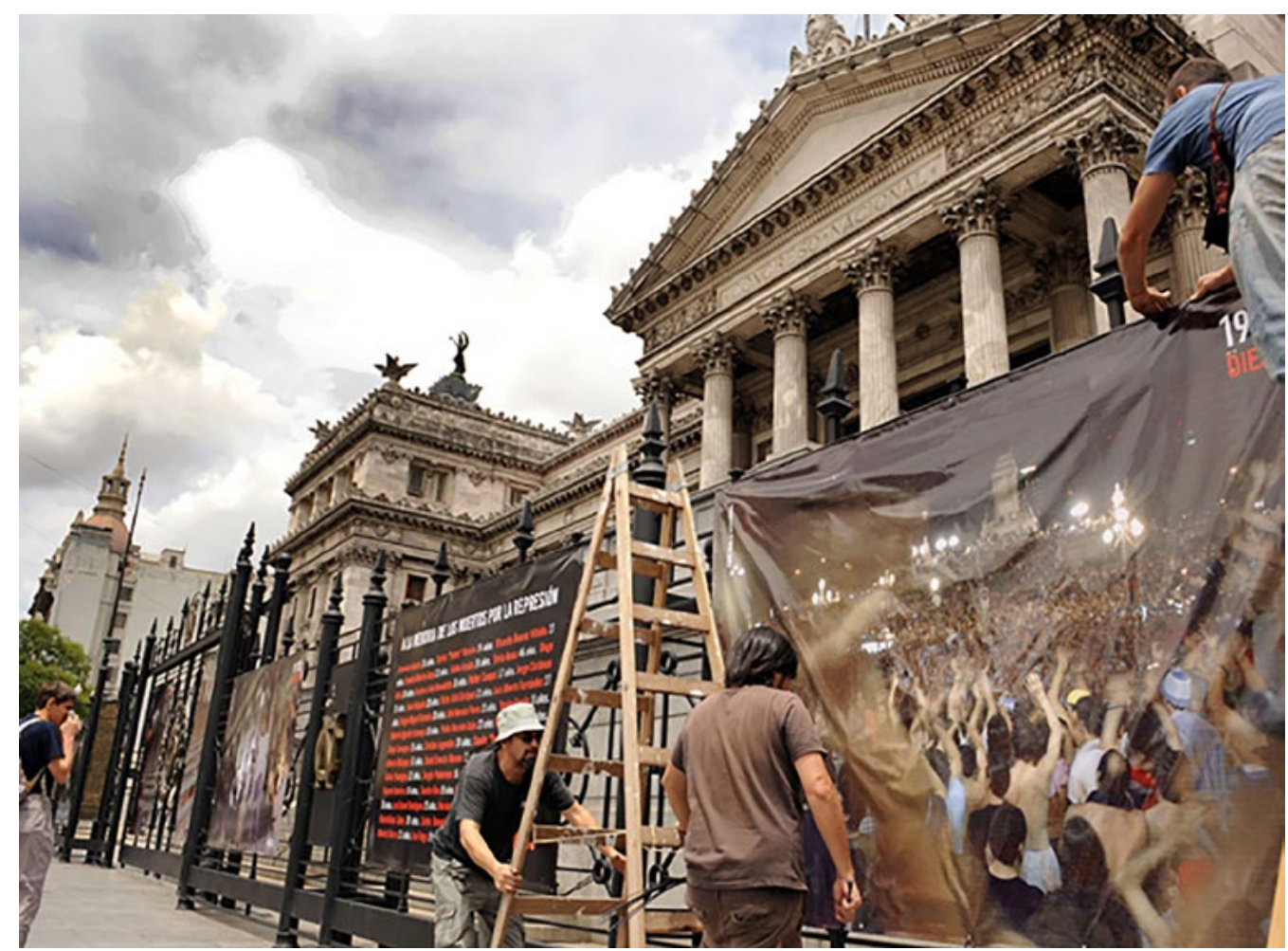

[ Figura 6. Fotografía en la instancia de colgar las gigantografías en la reja del Palacio del Congreso. ] Fuente: ARGRA 


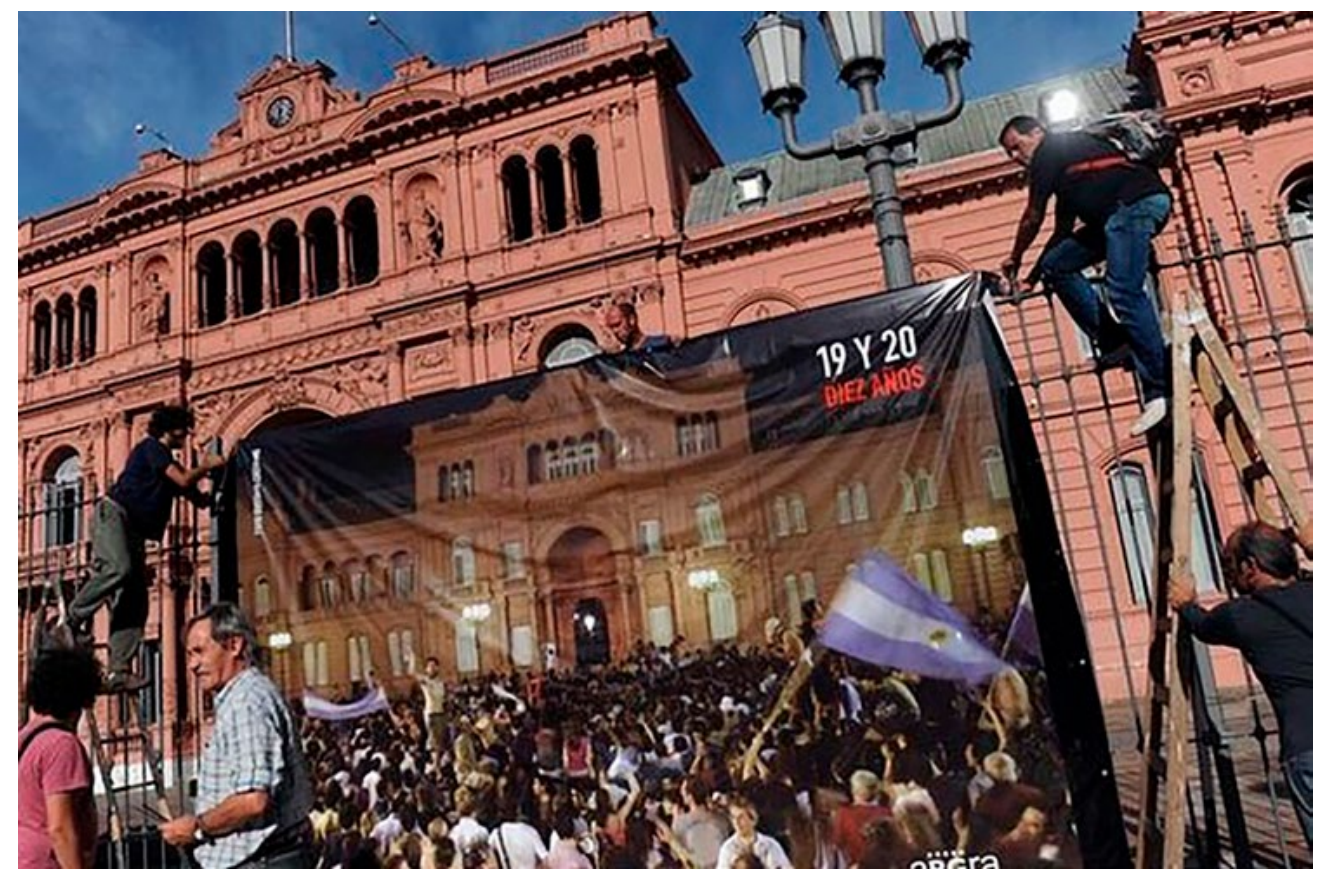

[ Figura 7. Fotografía del colgado de las imágenes en el mismo sitio de la toma original frente a la Casa Rosada. ] Fuente: ARGRA

En el contexto de tratar de entender cómo se construye la capacidad performativa de la imagen, debemos considerar que, en realidad, éstas imágenes ya eran conocidas por haber sido publicadas en distintos medios. Lo que las imágenes mostraban -en primera instancia- sería la conocida capacidad performática simbólica. El valor socio-político, cultural, no estaba en discusión: cualquiera podía reconocer víctimas, contexto y victimarios. Pero ¿se habría producido el mismo efecto de rechazo si hubiesen repartido las fotos en un folleto o un álbum?

Claramente fue el aspecto cuantitativo, material: la cantidad de imágenes, el lugar de emplazamiento y el tamaño de las fotografías que viabilizó la performatividad indicial, la «fuerza bruta del hecho» diría Peirce (CP 1.427, 1896)7. Por último, también es posible la identificación de una performatividad icónica, es decir, valorar los efectos que genera la imagen por sus mismas cualidades formales -proporción, encuadre, proxémica, Teoría de la Gestalt-, con un relativo nivel de independencia del efecto cognitivo-simbólico.

Así puede verificarse que -incluso históricamente-se cumple siempre esta construcción del conocimiento a partir de una necesidad o ley cultural, de lo simbólico a lo indicial y a lo icónico. A esta operación semiótica Peirce la ilustraba con la expresión «Symbols grow» (CP 2.302, 1895).

Por otro lado -y aunque el ejemplo que traemos propone una coyuntura extrema- podemos sostener que las imágenes nunca son solamente objeto de una afectación cognitivo- simbólica, sino que siempre -en mayor o menor medida- involucran una performatividad indicial y una performatividad icónica. A esta conjunción la llamamos performatividad contingente (Acebal et al. 2014: 87-88). Es esta performatividad contingente de las imágenes la que creó las condiciones para que lo que venía siendo habitual -un árbol navideño monumental circundado por una reja- se vuelva visual, material y políticamente inadmisible y fuera incendiado [Fig. 8 y 9 ]. 


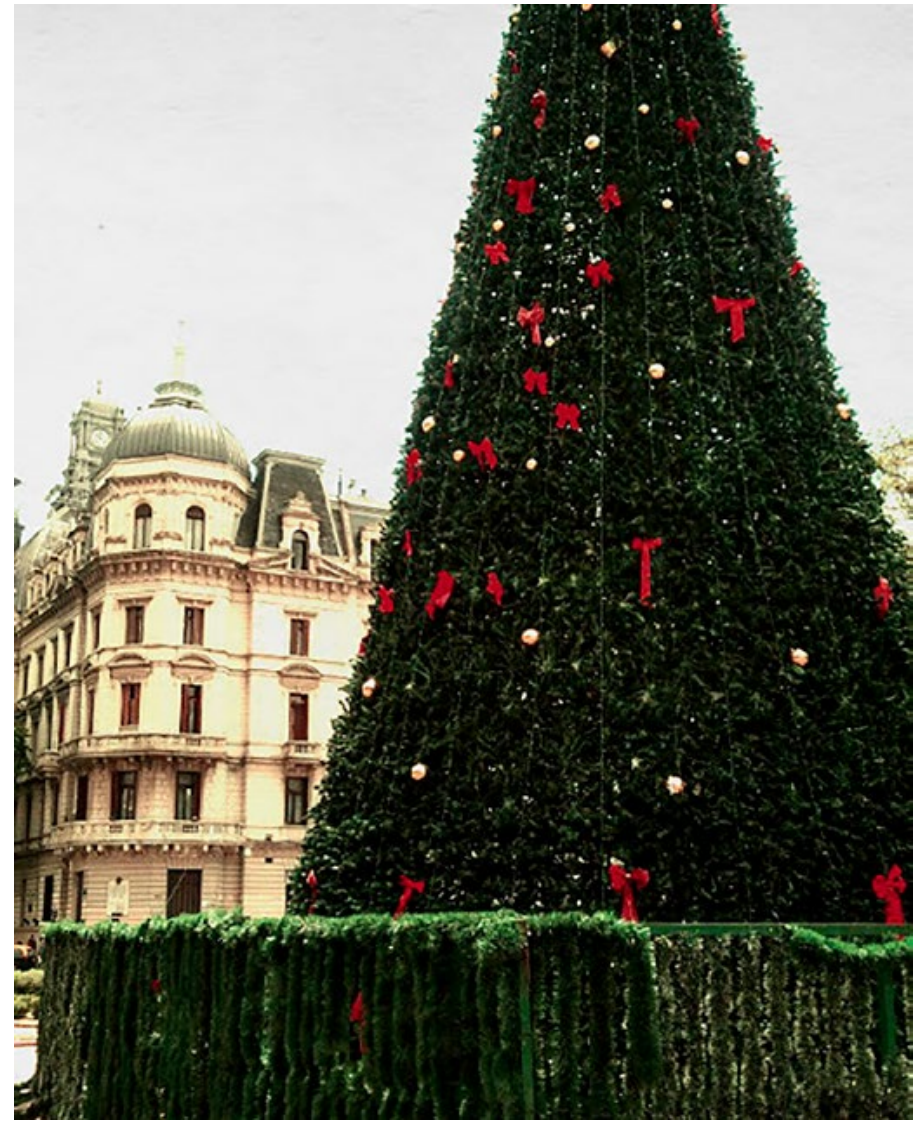

[ Figura 8. Imagen del árbol de Navidad que el gobierno de la Ciudad de Buenos Aires instalaba todos los años en la Plaza de Mayo frente a la Casa Rosada. ] Fuente: Cristina Voto.

[ Figura 9. Finalmente, el árbol de Navidad rodeado por una alta valla metálica es considerado una afrenta, debido a la performatividad contingente lograda por las imágenes y, por lo tanto, quemado. ]

Fuente: Cristina Voto.

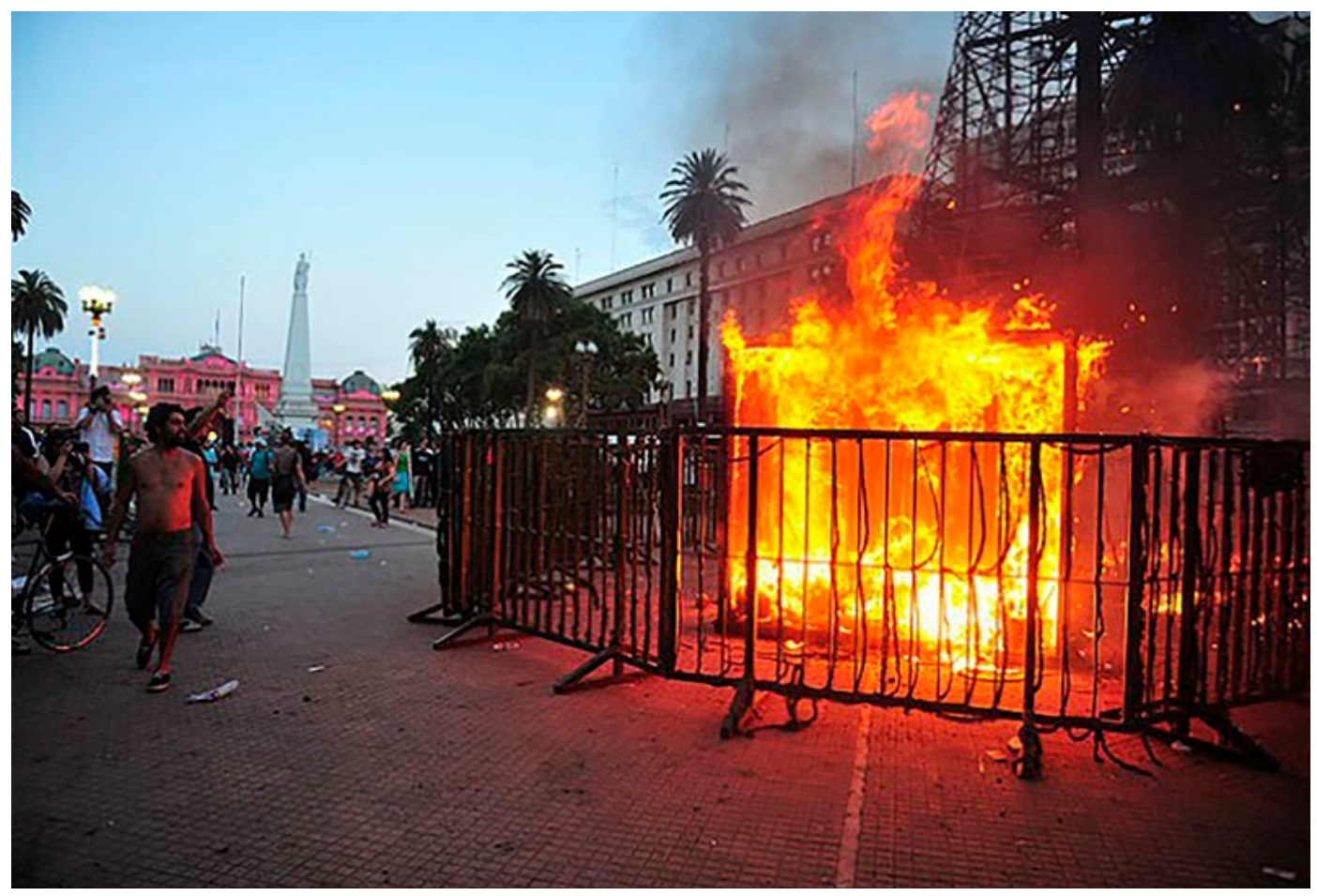




\section{EN ESTE NÚMERO}

\section{EL PRESENTE Número de la revista LA TADEO} DEARTE se organiza en cuatro apartados que, nuevamente, recorren distintos aspectos de la problemática de la imagen.

En el apartado Nuevos soportes, Gabriele Marino propone un abordaje semiótico para un fenómeno que ha crecido desde el 2000, los memes de Internet. El autor repone en su artículo tanto la genealogía del término a partir del trabajo fundacional de Richard Dawkins, como sus posteriores cuestionamientos desde la semiótica, y en especial de la llamada biosemiótica. Junto con esto, se propone devolverle al fenómeno su carácter específico en el marco de la Internet, como espacio de constitución y circulación. Para esto, plantea elaborar una definición, una tipología y el análisis de ciertos casos cuya difusión los ha vuelto paradigmáticos. Finalmente, complementa este desarrollo con dos aspectos que serían específicos del meme de Internet: su carácter dialógico y su propagabilidad, cualidades dadas por las propiedades intrínsecas del contenido -en términos tecnológicos, económicos y comunicativos-y de las redes sociales online y offline.

Isabella Sánchez explora en las transformaciones que experimenta la imagen al formar parte de un fenómeno que se ha ido difundiendo desde el año 2012: el GIF, producido por la plataforma de internet Tumblr. Con este objetivo, la autora construye una genealogía con la que busca filiar a estas imágenes digitales con los antiguos zoótropos y el taumatropos -artefactos que funcionaban mediante un movimiento manual-, las primeras experiencias fotográficas que buscaron capturar el movimiento, el cine y la misma literatura. De este modo, las imágenes digitales, con su baja calidad y movimiento, ganan un nuevo espesor, lo que le permite a la autora retomar nociones de estos otros lenguajes para proponer una tipología de GIF, destinada a facilitar el acceso a este fenómeno que los nuevos dispositivos vuelven cada vez más masivo.

Franco Giardino dedica su trabajo a indagar en la influencia que el consumo de imágenes ejerce en la enseñanza y la práctica arquitectónica, y a proponer estrategias metodológicas su uso durante los procesos de proyecto arquitectónico. Con este objetivo, destina parte de su trabajo a desarrollar la dimensión política operante en la percepción y producción de las imágenes, andamiado con los desarrollos de Jacques Rancière y su propuesta de un régimen estético de las artes, operante en la percepción contemporánea de las imágenes. A estos planteos más generales, Giardino los complementa con una reflexión acerca del rol de las imágenes en la enseñanza y en la profesión de la disciplina arquitectónica. Finalmente, el texto muestra el modo en que estas reflexiones permiten la elaboración de una estrategia didáctica denominada Imaginación y Arquitectura, destinada a asistir a estudiantes y profesionales en las primeras etapas del proyecto arquitectónico.

El artículo de Andrés Gabriel Villamizar se inscribe en todo un grupo de investigaciones destinadas a construir un uso reflexivo de las imágenes en la enseñanza, con especial atención, en su caso, en la enseñanza del inglés para adultos. El trabajo de Villamizar tiene la virtud de reconstruir las creencias sobre las imágenes de aquellos docentes de inglés que trabajan diariamente con materiales visuales, pero sobre las que no han desarrollado el mismo nivel de comprensión al que manifiestan sobre el lenguaje verbal. De este modo, el artículo muestra la necesidad de trabajar sobre una alfabetización visual que les devuelva a las imágenes el nivel de complejidad y protagonismo que poseen en los textos multimodales, recurrentes en la enseñanza del lenguaje verbal.

En el apartado Documentos, Guillermo Forero Cruz ofrece un recorrido por el Patrimonio Audiovisual, de la Universidad Jorge Tadeo Lozano. Se trata de un proyecto que se propone la reunión del material gráfico, fotográfico, sonoro y de imagen en movimiento que permite reconstruir - pero también forjar- la historia de la Universidad. El texto de Forero Cruz y las imágenes que lo integran nos invitan a reflexionar sobre el actual interés de las instituciones por transformar su historia en un espacio de investigación y en un instrumento para construcción de una memoria compartida. 
El artículo de Claudia Angélica Reyes Sarmiento es el resultado de estudios sobre el Star System y la mujer a partir de la documentación que ofrecen los medios masivos de información y el diseño gráfico -comercial y publicitario-de los años 30 en Colombia. Se verifica cómo el Diseño Gráfico construye una información visual idealizada para la mirada masculina, que se contradice con otras exigencias de la época: cumplir con los roles de madre y esposa protectora del hogar y tener un cuerpo fuerte y resistente.

En el apartado Imagen de la ciudad, Carlos Hilger reconstruye la génesis histórica -y también la mítica- de una obra icónica de la ciudad de Buenos Aires, el «Pasaje Barolo», un edificio concebido como «Monumento al Genio Latino», Dante Alighieri. El texto construye un relato que se remonta no solo al texto de Dante, sino hasta aquellos otros textos precursores que también buscaron en sus páginas la construcción de un cosmos. De este modo, Hilger nos lleva desde los tiempos clásicos hasta principios del siglo XX, al momento de encuentro entre el arquitecto Palanti y el comerciante italiano Barolo, radicado en Buenos Aires. En esta historia, la construcción de la obra adquiere un carácter mitológico y tan simbólico como las partes que componen el edificio y las figuras proyectadas sobre los visitantes en sus arcos y pasillos.

David Vélez Santamaría se propone explorar el caso del Neobrutalismo, movimiento arquitectónico de la segunda posguerra en Inglaterra. El artículo combina las apreciaciones contemporáneas al fenómeno del crítico Reyner Banham con las lecturas retrospectivas que podemos realizar desde el presente. Se despliegan así diferentes miradas sobre estas obras, tanto aquellas que muestran la ampliación de recursos que permitió este «retorno a lo primitivo», como su carácter de «principio de realidad» comprensible en el contexto de una Europa destruida por las guerras. Santamaría también logra mostrar los puntos de encuentro entre este movimiento y textos y obras de Le Corbusier, arquitecto paradigmático del movimiento moderno en la Arquitectura.

Finalmente, en el apartado Galería, Joan Deulofeu Gómez nos ofrece un repertorio de imágenes que pueden ser alteradas, recortadas, vueltas a pegar y recombinadas para generar otras como una invitación al juego. El autor nos propone El Empordà -en la costa noreste de Catalunya, España, donde él mismo nació y creció- para realizar fotomontajes, collages, imágenes inventadas y recrear tanto el espacio físico como el mental de esa zona turística con valores territoriales y culturales como casa, teatro y castillo de Salvador Dalí y su esposa Gala.

A pesar de provenir de comunidades diversas de investigación, sobre la cultura visual o artística, la antropología cultural, la historia, la semiótica cognitiva, y tratando casos de estudio de diferentes contextos temporales y geográficos, los artículos presentados en este volumen abordaron desde distintos puntos de vista los conceptos, la materialización y la producción, y los distintos valores socio-culturales y políticos de la imagen que indicábamos al principio. Desde la pertenencia histórica, la estrategia formal, la capacidad agentiva y performática, el archivo, la memoria y la cultura conmemorativa, sin olvidar la técnica y la tecnología de reproducción, son todas cuestiones inherentes a la especificidad de la imagen -un tema no menor en el campo más vasto del arte-, que se trataron de una u otra manera en los trabajos presentados.

Con este nuevo número de LA TADEO DEARTE somos perfectamente conscientes que el tema no queda agotado, solo esperamos haber aportado un granito de arena más en el desierto de la imagen. 
NOTAS

1 Para una primera respuesta, véase «Retórica revisitada» en Guerri (2016, 79-96).

2 Un mayor desarrollo de esta concepción puede encontrarse en Guerri (2012).

3 Para una introducción a los conceptos básicos de la semiótica peirceana en español, véase Deely (1990 [1996]), Magariños de Morentin (2008), Restrepo (1993) o Restrepo (2010).

4 A los efectos prácticos, utilizamos la nomenclatura más conocida de la propuesta peirceana que responde a la lógica triádica de las tres categorías: Primeridad, Segundidad y Terceridad., véase Guerri (2016, 3-23).

5 Véase «Los cinco sentidos son tres» en Guerri (2016, 66-69).

\section{R E F E E N C I A S}

- Austin, John L. Hacer cosas con palabras. Barcelona: Paidós, 1981

- Acebal, M., Bohórquez Nates, M., Guerri, C. y Voto, C. «La manumisión de las imágenes». Lexia. Revista de Semiótica, 17-18, 2014, 71-90.

- Deely, John. Los fundamentos de la semiótica. México: Universidad Iberoamericana, 1996.

- Fletcher, Sir Banister. A History of Architecture on the Comparative Method. Londres: Batsford, 1896.

- Guerri, Claudio. Lenguaje Gráfico TDE. Más allá de la Perspectiva. Buenos Aires: EUDEBA, 2012.

- Guerri, Claudio et al. Nonágono semiótico. Un modelo operativo para la investigación cualitativa. Buenos Aires: EUDEBA, 2016.

- Jannello, César V. Diseño, lenguaje y arquitectura. Buenos Aires: FAU-UNBA, Textos de Cátedra, 1980.
6 En este contexto de razonamiento lógico, vale la pena hacer notar que la tradición milenaria verbo céntrica hizo desestimar también a John Austin que para validar la acción de bautizar -ya sea un ser humano o un barco- hace falta, además de la palabra -aspecto simbólico-, todo un espacio y un entorno humano concreto -aspecto indicial-y un representante con el poder formal para realizarlo -aspecto icónico-. La performatividad siempre es contingente, hay siempre un aspecto icónico, indicial y simbólico que se actualizan simultáneamente.

7 Sigo la práctica de citar los Collected Papers of Charles Sanders Peirce con CP, volumen, número de párrafo y año del escrito.
- Magariños de Morentin, Juan. Semiótica de los bordes. Córdoba (Arg.): 2008.

- Peirce, Charles S. «Cómo esclarecer nuestras ideas» en Obra filosófica reunida de N. Houser y C. Kloesel (eds.), I, 172-188. México: FCE, 2012.

- $\quad$ Peirce, Charles S. Collected Papers of Charles Sanders Peirce. C. Hartshorne y P. Weiss (eds.). Cambridge: Harvard UP, 1931-58.

- Restrepo J., Mariluz. Ser-Signo-Interpretante. Filosofía de la representación en Charles S, Peirce. Bogotá: Significantes de papel, 1993.

- Restrepo J., Mariluz. Representación, relación triádica en el pensamiento de Charles S. Peirce. Bogotá: UNC, 2010.

- Volli, Ugo. «Some possible development of the concept of iconism». Versus 3, (1972): 14-30. 